\title{
Separation of chemical groups from bio-oil water-extract via sequential organic solvent extraction
}

\author{
Shoujie Ren ${ }^{\mathrm{a}}$, X. Philip Ye ${ }^{\mathrm{a} *}$, Abhijeet P. Borole ${ }^{\mathrm{b}}$ \\ ${ }^{a}$ Biosystems Engineering \& Soil Science, University of Tennessee, Knoxville, TN, 37996. U.S.A. \\ ${ }^{b}$ Bioscience Division, Oak Ridge National Laboratory, Oak Ridge, TN 37831. U.S.A. \\ *Corresponding author: Phone: +1-(865)-974-7129. E-mail: xye2@utk.edu
}

\begin{abstract}
The chemical complexity of bio-oil aqueous phase limits its efficient utilization. To improve the efficiency of the bio-oil biorefinery, this study focused on the separation of chemical groups from the bio-oil water-extract via sequential organic solvent extractions. Due to their high recoverability and low solubility in water, four solvents (hexane, petroleum ether, chloroform, and ethyl acetate) with different polarities were evaluated, and the optimum process conditions for chemical extraction were determined. Chloroform had high extraction efficiency for furans, phenolics, and ketones. In addition to these classes of chemical, ethyl acetate had a high extraction efficiency for organic acids. The sequential extraction using chloroform followed by ethyl acetate resulted in $62.2 \mathrm{wt} \%$ of original furans, ketones, alcohols, and phenolics being extracted into chloroform, while $62 \mathrm{wt} . \%$ acetic acid was extracted into ethyl acetate, leaving behind a high concentration of levoglucosan $(\sim 53.0 \mathrm{wt} . \%)$ in the final aqueous phase. Chemicals separated via the sequential extraction could be used as feedstocks in a biorefinery using processes such as catalytic upgrading of furans and phenolics to hydrocarbons, fermentation of levoglucosan to produce alcohols and diols, and hydrogen production from organic acids via microbial electrolysis.
\end{abstract}

Keywords: Bio-oil aqueous phase, Organic solvent, Solvent extraction, Chemical groups 


\section{Introduction}

Bio-oil from biomass pyrolysis is a promising feedstock for the production of transportation

fuels and value-added chemicals $[1,2]$. However, some disadvantages make it difficult to directly use bio-oil as a transportation fuel. Bio-oil contains hundreds of chemicals that are classified according to their functional groups, including phenolics, furans, organic acids, ketones, aldehydes, esters, and anhydrosugars [3,4]. Unlike petroleum oil, most chemicals in bio-oil are unstable oxygenated compounds, amounting to as high as $40 \mathrm{wt} \%$ of oxygen [5]. Biooil also has a significant content of water generally ranging from 15-30 wt.\%, depending on the different types of biomass and pyrolysis processes [5]. Furthermore, organic acids are the major contributors to the acidity of bio-oil, causing corrosion that requires special containers for the storage and transportation.

To recover and utilize the water-soluble chemicals, phase separation of bio-oil into an organic phase and an aqueous phase by adding water has been investigated [2, 6-9]. The extraction efficiency of chemicals in bio-oil by water is highly dependent on the polarity and solubility of the chemicals. Because of their high polarity and solubility in water, levoglucosan and organic acids, such as acetic acid, have high distribution coefficients in water, resulting in a high concentration in the aqueous phase. Furans, such as furfural and furanone, have a distribution coefficient similar to acetic acid [6]. Some phenolic compounds, such as syringol and guaiacol, have low polarity, but due to their low initial concentration in crude bio-oil, these compounds also have a high distribution coefficient to water and a considerable fraction can also be extracted by water [6]. Thus, the bio-oil aqueous phase is a complex mixture requiring further separation to be efficiently utilized.

Due to the multitude of chemicals present in the aqueous phase, a variety of applications of bio-oil aqueous phase have been investigated, including aqueous phase reforming [10-12], 
51 extraction and recovery of value-added chemicals, such as acetic acid [13,14], and ethanol

52 production via hydrolysis and fermentation of levoglucosan $[12,15]$. Recently, a novel

53 application of the aqueous phase for hydrogen production has been reported via a microbial

54 electrolysis (MEC) process [16]. Certain biological processes, such as microbial fermentation,

55 are negatively affected by furans and phenolics [12, 16-18]. Therefore, the removal of non-

56 desirable compounds from the bio-oil aqueous phase is required.

57 Several methods including distillation, solvent extraction, and column chromatography have

58 been developed for separating and recovering the various components and to characterize bio-oil

59 and the associated aqueous phase [7, 13, 19-22]. Among these methods, solvent extraction is

60 considered cost-effective, as it can be operated at room temperature and atmospheric pressure

61 [23]. Garcia-Perez et al. investigated different organic solvents to fractionate the chemicals for

62 characterization [24]. Wei et al. found that chloroform had good performance in extracting

63 phenolic compounds [7]. However, a considerable amount of furans, ketones, and alcohols were

64 still detected by gas chromatography and mass spectrometry (GC/MS) in bio-oil aqueous phase

65 after organic solvent extraction [7]. Moreover, organic acids and levoglucosan were not well

66 separated by these organic solvents. Therefore, only using a single solvent might not sufficiently

67 extract and separate these chemicals from the bio-oil aqueous phase.

68 Separating compounds in the bio-oil aqueous phase into different chemical groups is

69 practically useful. It minimizes the effects of non-desirable chemicals on the application of

70 specific chemical groups, develops strategies for the application of the bio-oil aqueous phase,

71 and improves its application efficiency. Due to the very low concentration of individual

72 compounds of furans, alcohols, ketones, and phenolics in the bio-oil aqueous phase, isolating

73 these chemicals individually would be difficult and costly. Therefore, separating these chemicals 
74 as a group (Group 1) may be more practical. Due to the significant amount of organic acids

75 (Group 2) and anhydrosugars (Group 3) in the bio-oil aqueous phase, separating these two

76 chemical groups is feasible. Therefore, the purpose of this study was to develop a method to

77 separate these three chemical groups from bio-oil aqueous phase using organic solvents. Four

78 solvents including hexane, petroleum ether, chloroform, and ethyl acetate with different

79 polarities were first evaluated individually for chemical extraction. Optimum conditions and

80 extraction efficiency related to the different chemical groups were determined. According to

81 these analyses, a sequential extraction using chloroform followed by ethyl acetate were further

82 investigated for separating Group 1 (furans, alcohols, ketones, and phenolics), Group 2 (organic

83 acids) and Group 3 (anhydrosugars).

84

85 2. Materials and Methods

$86 \quad 2.1$ Materials

87 Air-dried switchgrass (Panicum virgatum L.) obtained from a local producer in East

88 Tennessee was used for the bio-oil production. The water content of the biomass was 7-8 wt. $\%$.

89 Before pyrolysis, the material was ground to less than a $2 \mathrm{~mm}$ particle size. The switchgrass is

90 composed of 34.1 wt.\% cellulose, 25.7 wt.\% hemicellulose, 18.8 wt.\% lignin, 14.2 wt.\%

91 extractives, and $2.7 \mathrm{wt} \% \%$ ash [25].

92 Hexane (a mixture of isomers, purity $>98.5 \%$ ), petroleum ether (ACS certified grade),

93 chloroform (purity $>99.0 \%$ ), and ethyl acetate (purity $>99.5 \%$ ) purchased from Thermo Fisher

94 Scientific (Waltham, MA) were used as organic solvents for chemical extraction from bio-oil

95 aqueous phase (BOAP). All these chemicals were used as received. Fifteen external standards,

96 all purchased from Sigma-Aldrich (St. Louis, MO), were used for quantifying compounds in the

97 BOAP. 


\subsection{Crude bio-oil production and bio-oil aqueous phase separation}

A schematic diagram of the experiment for the separation of chemical groups by a sequential extraction is shown in Fig. 1A. The process includes bio-oil production, aqueous phase separation, and organic solvent extractions. The separated chemical groups can be integrated into a biorefinery for the production of fuels and chemicals (Fig. 1B).

A semi-pilot scale auger pyrolysis system (Proton Power, Inc., Lenoir City, TN) was used to pyrolyze switchgrass for bio-oil production. A detailed description of the pyrolysis system was provided elsewhere [25]. The pyrolysis was conducted at $500{ }^{\circ} \mathrm{C}$ with a residence time of 72 seconds.

The separation of the bio-oil aqueous phase was achieved by simply adding water to crude bio-oil [26]. First, the crude bio-oil was mixed with four times by weight of distilled water. Then, the mixture was shaken vigorously using a mini vortexer (Model MS1 S7, Fisher Scientific) until a homogeneous mixture was formed. The mixture was stored at $4{ }^{\circ} \mathrm{C}$ overnight, followed by centrifugation using an IEC Model 120 clinical centrifuge (International Equipment Company) at a relative centrifugal force $(\mathrm{RCF})$ of $2,400 \mathrm{~g}$ for 30 minutes to accelerate phase separation. After centrifugation, bio-oil aqueous phase (BOAP I) on top was collected and analyzed, as described below.

Physical properties of crude bio-oil and BOAP I, including density, $\mathrm{pH}$, viscosity, water content, solid content, ash content, and total acid number, were measured in triplicate. Density was measured according to the ASTM D1217 (2012) standard [27], and pH was measured with an Extech pH meter. A Schott TitroLine Karl Fischer volumetric titrator was used to measure water content according to ASTM D4377 (2011) [28]. Viscosity was measured at $40{ }^{\circ} \mathrm{C}$ with serialized Schott Ubbelohde capillary viscometers according to ASTM D445 (2012) [29]. Ash content was measured according to ASTM D482 (2013) at $575{ }^{\circ} \mathrm{C}$ [30]. The solid content was 
122 determined according to Boucher et al. [31]. Total acid number (TAN) was measured by

123 titrating bio-oil $(0.1 \mathrm{~g})$ or BOAP I (0.2 g) in a solvent of water, isopropyl alcohol and toluene

124 (volume ratio of water: isopropyl alcohol: toluene = 1: 99:100) with $0.1 \mathrm{M} \mathrm{KOH}$ isopropyl

125 alcohol solution to an end point of pH 11 according to ASTM D664 (2011) [32].

126

127

128

129

130

131

132

133

134

135

136

137

138

139

140

141

142

143

144

\subsection{Chemical extraction from bio-oil aqueous phase}

The separated BOAP I was used for extraction experiments. Four organic solvents, hexane, petroleum ether, chloroform, and ethyl acetate, were first individually investigated to separate chemicals from BOAP I. Four different volumetric ratios of solvent to BOAP I $(0.5: 1,1: 1,2: 1$, and 3:1) were employed to determine the effect of solvent-to-feed ratio (S/F ratio) on the chemical extraction. A fixed volume of BOAP I at $20 \mathrm{~mL}$ was weighed and measured into a 100 $\mathrm{mL}$ beaker. Then a predesignated volume of organic solvent was added into the beaker. The mixture of BOAP I and the organic solvent was magnetically stirred for $30 \mathrm{~min}$. After stirring, the mixture was transferred to a separatory funnel and left undisturbed for 24 hours to allow phase separation. During the stirring and separation, the beaker and funnel were sealed to minimize solvent evaporation. After separation, the solvent phase and BOAP II were collected and weighed. Chemicals extracted to the organic solvent were recovered by evaporating the organic solvent via a rotary evaporator at $40^{\circ} \mathrm{C}$.

First, distribution coefficient and extraction efficiency [33] were used to evaluate the four solvents in extracting BOAP I. The distribution coefficient $\left(D_{i}\right)$ is defined as the ratio of equilibrium mass concentration $(\mathrm{g} / \mathrm{L})$ of compounds in the solvent ( $i$ indicates six groups based on their functional groups: acids, furans, alcohols, ketones, phenolics, and levoglucosan, that is the only anhydrosugar detected) to their equilibrium mass concentration in BOAP I, according to Equation 1. 


$$
D_{i}=\frac{\text { mass concentration of } i \text { in solvent }}{\text { mass concentration of } i \text { in } B O A P I}
$$

(Equation 1)

Extraction efficiency $\left(X_{j}\right)$ is defined as the mass percentage (wt.\%) of 15 individual chemical compounds $(j)$ transferred from BOAP I to the organic solvent after the extraction process according to Equation 2.

$$
X_{j}=\frac{\text { mass of } j \text { in } B O A P I-\text { mass of } j \text { in BOAP II }}{\text { mass of } j \text { in BOAP I }} \times 100 \%
$$

According to the results evaluating the four solvents, chloroform and ethyl acetate were chosen for sequential extraction to separate the chemical groups from BOAP I, which was first extracted by chloroform to recover furans, ketones, and phenolics. After chloroform extraction, BOAP II and the solvent phase were collected and weighed. BOAP II was further extracted using ethyl acetate. The organics extracted to chloroform and ethyl acetate were recovered by evaporating the organic solvents via a rotary evaporator at $40{ }^{\circ} \mathrm{C}$. BOAP II and III were collected and analyzed. The experiment was performed in triplicate.

\subsection{Chemical identification and quantification by GC/MS, GC-FID and HPLC}

Chemical compounds in BOAP I were identified using gas chromatography/mass spectrometry (GC/MS). A Shimadzu GC/MS (QP2010S) with a Restek Rtx-5MS capillary column $(30 \mathrm{~m} \times 0.25 \mathrm{~mm} \times 0.25 \mu \mathrm{m})$ was used. The column temperature was programmed at $45^{\circ} \mathrm{C}$ for $3 \mathrm{~min}$ and increased to $150{ }^{\circ} \mathrm{C}$ at $5{ }^{\circ} \mathrm{C} / \mathrm{min}$; then, it was further increased to $260{ }^{\circ} \mathrm{C}$ at $10{ }^{\circ} \mathrm{C} / \mathrm{min}$ and held for $7 \mathrm{~min}$ at the final temperature. The inlet was set at $240{ }^{\circ} \mathrm{C}$, and sample injection was made in a split mode (1:20). The compounds were identified by comparing their mass spectra with those from the National Institute of Standards and Technology (NIST) mass spectral data library.

The acids, levoglucosan, hydroxymethylfurfural, furfural, phenol, and 1,2-benzenediol in BOAP I-III were quantified using a high pressure liquid chromatography system (HPLC, Jasco 
2000Plus, Jasco Analytical Instruments, Easton, MD) equipped with a MD-2018 plus photodiode array detector (PAD), a RI-2031 Plus intelligent RI detector, and an AS-2055 plus auto sampler [26]. The liquid chromatography was conducted at $50{ }^{\circ} \mathrm{C}$ using a Bio-Rad column HPX-87H (300 $\times 8 \mathrm{~mm}$ ). The injected sample volume was $20 \mu \mathrm{L}$. The mobile phase was $5 \mathrm{mM} \mathrm{H}_{2} \mathrm{SO}_{4}$ in deionized water with a flow rate of $0.6 \mathrm{~mL} / \mathrm{min}$.

The following compounds in BOAP I-III, which have been reported in switchgrass bio-oil analysis [34-37], were quantified using a gas chromatography-flame ionization detector (GC-FID) with a HP-5 column $(30 \mathrm{~m} \times 0.32 \mathrm{~mm} \times 0.25 \mu \mathrm{m})$ : $2(5 \mathrm{H})$-furanone, 1-hydroxy-2-butanone, 1,3 propanediol, 3-methyl-1,2-cyclopentanedione, guaiacol, creosol, 2,6-dimethoxyphenol, 3ethylphenol . The same temperature program as that with GC/MS was used in the GC-FID. The compounds extracted to organic solvent phase were also quantified by the GC-FID. Compounds were quantified using external standards in both the HPLC and GC-FID analysis.

\section{Results and Discussion}

\subsection{Characterization of bio-oil and BOAP I}

The physical properties of crude bio-oil and BOAP I are shown in Table 1. The crude bio-oil obtained from the pyrolysis was an even mixture containing about $41.1 \mathrm{wt} . \%$ water. After aqueous phase separation, BOAP I showed a light yellow color containing about $90.8 \mathrm{wt} . \%$ water. After the separation, most polar compounds were extracted by water to BOAP I. The oligomers derived from lignin remained in the black and viscous organic phase. Due to the dilution by water, the $\mathrm{pH}$ in BOAP I slightly increased compared with the crude bio-oil, while the density, ash content, viscosity, and TAN decreased. 
GC/MS analysis showed that more than 50 compounds were detected in BOAP I. The

191

192

193

194

195

196

197

198

199

200

201

202

203

204

205

206

207

208

209

210

211

212

relative peak areas in GC/MS chromatogram were considered a useful indication of the relative abundance of chemicals, which has been used in bio-oil analysis [38-41]. Among these compounds, levoglucosan, acetic acid, furfural, and phenol were the most abundant as detected by GC/MS spectrometry. According to their functional groups, the detected compounds were classified into anhydrosugars, acids, furans, alcohols, phenolics, aldehydes, ketones, esters, and others (nitrogen-containing compounds). The distribution of these chemicals in BOAP I according to their relative GC/MS peak area is shown in Fig. 2.

Previous study has pointed out that levoglucosan, organic acids, alcohols, furans such as furfural, and acetol have high distribution coefficient in water [6]. After the bio-oil aqueous phase separation, the majority of these compounds can be extracted to the aqueous phase. Although phenolic compounds have a lower polarity than acids and furans, their low initial concentration in the crude bio-oil affords them a high distribution coefficient in water [6]. GC/MS analysis detected a number of phenolic compounds with small peaks in BOAP I, but these small peaks added up to a total relative area of about 28 area $\%$. A number of aldehydes, ketones, and esters with relatively small area percentage were also found in BOAP I.

Taking their high peak area percentages into account, 15 compounds were further quantified using GC-FID and HPLC, including two acids, three furans, two alcohols, six phenolics, one ketone, and one anhydrosugar (levoglucosan). These quantified chemicals accounted for about 53.9 wt.\% of total chemicals in BOAP I. The concentrations of these 15 compounds in BOAP I are presented in Table 2. Acids and anhydrosugars are the two major chemical groups extracted to BOAP I by water. Among the acids, acetic acid was detected at the highest concentration, which was about $16.54 \mathrm{~g} / \mathrm{L}$. The concentration of levoglucosan was about $18.99 \mathrm{~g} / \mathrm{L}$ in BOAP I. 
213 These two compounds were the most abundant chemicals observed in BOAP I. The

214 quantification of other chemicals in BOAP I showed that 1-hydroxy-2-butanone and

215 hydroxymethylfurfural with concentration of $2.25 \mathrm{~g} / \mathrm{L}$ and $1.37 \mathrm{~g} / \mathrm{L}$, respectively, are the major

216 chemicals following levoglucosan, acetic acid, and propionic acid. The total quantified

217 concentration of furans and alcohols were about $3.17 \mathrm{~g} / \mathrm{L}$ and $2.6 \mathrm{~g} / \mathrm{L}$, respectively. While the

218 individual phenolic compound had a low concentration in BOAP I, the total concentration of

219 quantified phenolic compounds added up to $1.5 \mathrm{~g} / \mathrm{L}$. These 15 quantified compounds (6 groups)

220 were used in the next step to evaluate the extraction efficiency of organic solvents from BOAP I.

221

222

\subsection{Effects of organic solvents on the extraction of total chemicals}

223

224

225

226

227

228

229

230

231

232

233

234

235

Fig. 3 shows the total mass percentages of the 15 chemicals extracted by the four different organic solvents. Among the four, hexane has the lowest affinity for chemicals in BOAP I, extracting less than $30 \mathrm{wt} . \%$. Petroleum ether has slightly higher affinity for chemicals than hexane, with the highest amount of chemicals extracted at $33.2 \mathrm{wt} \%$ from BOAP I. Chloroform has a higher affinity for chemicals than hexane and petroleum ether, in agreement with a previous report [7]. Ethyl acetate has the highest affinity for chemicals in BOAP I, followed by chloroform. These two can extract over $50 \mathrm{wt} . \%$ of total chemicals in BOAP I, due to their high polarity (polarity of chloroform at 4.1 and polarity of ethyl acetate at 4.4 ). In BOAP I , most chemicals present are oxygenated compounds, having high polarity and solubility in water [6]. Therefore, hexane and petroleum ether with very low polarity and solubility in water limit the dispersion of the oxygenated compounds. These results agree with previous studies suggesting that to recover more chemicals from BOAP I, solvents with high polarity, such as ethyl acetate and chloroform would be more preferable than hexane and petroleum ether with low polarity. 
The effect of different volumetric ratios of organic solvent to BOAP I (S/F ratio) was also

237 investigated (Fig. 3). With a S/F ratio of 0.5, all the four solvents showed poor extraction

238 performance for chemicals, with the maximum extracted amount being less than 22 wt. $\%$.

239 Increasing the $\mathrm{S} / \mathrm{F}$ ratio to 1 , the amount of chemicals extracted using hexane and petroleum

240 ether did not change significantly. However, the amount of extracted chemicals was significantly

241 increased using chloroform and ethyl acetate from $14.7 \mathrm{wt} . \%$ to $47.8 \mathrm{wt} . \%$ and $21.1 \mathrm{wt} . \%$ to 54.1

242 wt.\%, respectively. When the S/F ratio further increased to 2, the amount extracted by hexane,

243 petroleum ether and ethyl acetate, except for chloroform (increased only 2 wt.\%), significantly

244 increased as compared to that at $\mathrm{S} / \mathrm{F}$ ratio of 1 . This result indicates that the $\mathrm{S} / \mathrm{F}$ ratio of

245 chloroform to BOAP I at 1 is desirable for chemical extraction from an economic viewpoint,

246 consistent with a previous study [7]. When the S/F ratio further increased to 3, there were no

247 significant changes in extracted chemicals for all the tested solvents. Therefore, the optimum S/F

248 ratio were 2 for hexane, petroleum ether, or ethyl acetate and 1 for chloroform.

\subsection{Effects of solvents on the separation of 15 individual chemicals}

251 After organic solvent extraction of BOAP I, 15 chemicals in BOAP II were quantified using

252 GC-FID and HPLC to determine the effects of different organic solvents and S/F ratios on the

253 extraction of these chemicals. The extraction efficiency of individual chemical was calculated

254 according to Equation 2. The results are presented in Fig. 4 for Group 2 (two organic acids) and

255 Group 3 (one anhydrosugar) chemicals, and in Figs. 5 and 6 for Group 1 (twelve chemicals of

256 furans, alcohols, ketones, and phenolics).

257 As Fig. 4 shows, the extraction efficiencies for anhydrosugar (levoglucosan), and organic

258 acids (acetic acid and propionic acid) in BOAP I by hexane and petroleum ether were less than 
259

260

261

262

263

264

265

266

267

268

269

270 271 acetic acid and water.

272

273

274

275

276

277

278

279

280

281

10 wt.\%. Increasing loading of the two solvents did not significantly increase the extraction efficiency. Chloroform had low extraction efficiencies for anhydrosugar (less than 8.8 wt.\%) and organic acids (less than $14 \mathrm{wt} . \%$ for acetic acid and less than $3.9 \mathrm{wt} . \%$ for propionic acid) in BOAP I at low S/F ratios (volume ratio at 0.5 and 1 ); when the $\mathrm{S} / \mathrm{F}$ ratio increased to 3 , the extraction efficiencies for levoglucosan, acetic acid, and propionic acid increased to $11.1 \mathrm{wt} . \%$, $23.8 \mathrm{wt} . \%$, and $34 \mathrm{wt} . \%$, respectively. Ethyl acetate showed a performance similar to chloroform for the extraction of levoglucosan. The extraction efficiency for acetic acid was low using ethyl acetate when the $\mathrm{S} / \mathrm{F}$ was at 0.5 . However, when the $\mathrm{S} / \mathrm{F}$ ratios were increased to 2 and 3 , the extraction efficiency of acetic acid was significantly increased to $55 \mathrm{wt} . \%$ and $61.2 \mathrm{wt} . \%$, respectively. This result suggests that the $\mathrm{S} / \mathrm{F}$ ratio has great effect on acetic acid extraction. Because ethyl acetate can be used as a hydrogen bond acceptor in extraction [42], the increase in its loading provides more receptors for hydrogen bond, thus breaks the hydrogen bond between

Fig. 5 illustrates the extraction efficiencies for two alcohols (1-hydroxy-2-butanone, 1,3Propanediol), one ketone (3-methyl-1,2-cyclopentanedione), and three furans (hydroxymethylfurfural, 2(5H)-furanone, furfural) in BOAP I using the four organic solvents. Both hexane and petroleum ether had poor performance, even with increased loading, for the extraction of alcohols and the ketone. The extraction efficiencies using these two solvents varied greatly for the different compounds of furans. Extraction efficiencies for hydroxymethylfurfural were observed at less than 8 wt.\%. Hexane and petroleum ether had good extraction performance for $2(5 \mathrm{H})$-furanone with extraction efficiencies at about $58 \mathrm{wt} . \%$ and $59 \mathrm{wt} . \%$, respectively. Extraction efficiencies for furfural using hexane and petroleum ether were 13.3 wt.\% and 19.9 wt.\% at the $\mathrm{S} / \mathrm{F}$ ratio of 0.5 , respectively; when the $\mathrm{S} / \mathrm{F}$ ratio was increased to 2 , a significant 
282 increase in extraction efficiency for furfural was observed using both solvents. Further increasing

283 the S/F ratio to 3 using hexane and petroleum ether increased the extraction efficiencies for

284 furfural by about 7 and $10 \mathrm{wt} . \%$, respectively. However, the highest extraction efficiencies using

285 hexane and petroleum ether for furfural were achieved at 54.5 and 53.6 wt.\%, respectively.

286 Compared to hexane and petroleum ether, chloroform and ethyl acetate had a better extraction

287 performance for these chemical groups (two alcohols, one ketone, and three furans). The

288 extraction efficiencies using chloroform reached to about $29 \mathrm{wt} \%$ for 1-hydroxy-2-butanone, 10

289 wt.\% for 1,3-Propanediol, $68 \mathrm{wt} \% \%$ for 3-methyl-1,2-cyclopentanedione, $54 \mathrm{wt} \%$ for

290 hydroxymethylfurfural, $63 \mathrm{wt} . \%$ for $2(5 \mathrm{H})$-furanone, and $95 \mathrm{wt} . \%$ for furfural at the low S/F

291 ratio of 0.5 . When the $\mathrm{S} / \mathrm{F}$ ratio increased to 1 , the extraction efficiencies for 1-hydroxy-2-

292 butanone, 1,3-Propanediol, 3-methyl-1,2-cyclopentanedione, and hydroxymethylfurfural greatly

293 increased to $48.1 \mathrm{wt} . \%, 19 \mathrm{wt} . \%, 81 \mathrm{wt} . \%$, and $69.6 \mathrm{wt} . \%$, respectively. When the S/F ratio

294 increased to 2, the extraction efficiencies for these four compounds further increased to $57 \mathrm{wt} . \%$,

29536 wt.\%, 89 wt.\% and 82 wt.\%, respectively. Further increasing the S/F ratio to 3, the extraction

296 efficiency for 1,3-Propanediol increased to $56 \mathrm{wt} . \%$ while only a slight increase was observed for

297 the other three compounds. No significant change in the extraction efficiency was observed for

298 2(5H)-furanone and furfural when the $\mathrm{S} / \mathrm{F}$ ratio was increased from 0.5 to 3 . The extraction

299 efficiency for $2(5 \mathrm{H})$-furanone by ethyl acetate was higher than that by chloroform. However, the

300 extraction efficiency for 1-hydroxy-2-butanone, 3-methyl-1,2-cyclopentanedione,

301 hydroxymethylfurfural, and furfural by ethyl acetate was lower than that by chloroform,

302 especially at low solvent loading (S/F ratio at 0.5 and 1$).$

Hexane and petroleum ether had good performance for the extraction of phenolic

304 compounds (3-ethylphenol, guaiacol, 2,6-dimethoxyphenol, and creosol) as shown in Fig. 6. 
When the S/F ratio was increased to 2 , all creosol in BOAP I was extracted to solvents. At this S/F ratio, extraction efficiencies for 3-ethylphenol, guaiacol, and 2,6-dimethoxyphenol were about 73.5 wt. $\%, 80.1$ wt. $\%$, and 36.8 wt. $\%$, respectively, by hexane, and 68.5 wt. $\%, 74.4$ wt. $\%$ and $51.2 \mathrm{wt} . \%$, respectively, by petroleum ether. When the S/F ratio increased to 3 , the changes of 3-ethylphenol, guaiacol, and 2,6-dimethoxyphenol were insignificant. Hexane showed a poor extraction performance for 1,2-benzenediol and phenol; the highest extraction efficiencies for these two chemicals were $7 \mathrm{wt} . \%$ and $20 \mathrm{wt} . \%$, respectively, when the S/F ratio was increased to 3. Petroleum ether had a slightly better performance for 1,2-benzenediol and phenol than hexane. But the highest extraction efficiency was observed at $12.6 \mathrm{wt} . \%$ for 1,2-benzenediol and 35.5 wt.\% for phenol. Compared to hexane and petroleum ether, chloroform and ethyl acetate showed superior extraction efficiency for phenolic compounds (Fig. 6). All guaiacol, 2,6dimethoxyphenol, and creosol were extracted to solvents even at the low $\mathrm{S} / \mathrm{F}$ ratio of 0.5 , suggesting that the two had very high affinity for the three compounds. Extraction efficiency for phenol and 3-ethylphenol using chloroform was over 94 wt.\% and 87 wt.\% respectively, while the extraction efficiency for these two chemicals using ethyl acetate was at $100 \mathrm{wt} \%$ and 90 wt.\%, respectively. Chloroform had low affinity for 1,2-benzenediol as indicated by the extraction efficiency of only about $36 \mathrm{wt} . \%$. However, ethyl acetate showed a high affinity for 1,2-benzenediol resulting in an extraction efficiency of over $96 \mathrm{wt} . \%$ at a S/F ratio of 2. According to the above analyses, the extraction efficiency by the organic solvents for chemicals in BOAP I was not only affected by the different solvents and S/F ratios, but also subjective to the different chemical groups. Generally, chloroform had high extraction efficiency for furans, alcohols, and phenolics, while ethyl acetate had high extraction efficiency for organic acids in addition to furans and phenolics, indicating non-selective extraction by ethyl acetate. 
328 The optimum S/F ratio and extraction efficiency by the four solvents for the 15 quantified 329 chemicals are summarized in Table 3.

To further understand the effects of solvent on the chemical extraction, the distribution coefficients of six chemical groups were summarized in Fig. 7. The distribution coefficient of

332 furans, alcohols, or ketones in hexane and petroleum ether was less than 0.6, much lower than 333 that in chloroform or ethyl acetate. Due to the large difference in polarity between the solvent 334 and the chemicals to be extracted, the distribution coefficients of levoglucosan and acids in 335 hexane and petroleum ether were very low, generally less than 0.1 (Fig. 7). These results indicate 336 that hexane and petroleum ether cannot be efficiently used to extract furans, alcohols, ketones, 337 anhydrosugars, and organic acids. The highest distribution coefficient of alcohols and furans in 338 chloroform was observed at 0.79 and 4.49, respectively. Compared to those in chloroform, the 339 distribution coefficients of alcohols and furans in ethyl acetate were lower. Therefore, 340 chloroform would be the preferred choice for the extraction of alcohols and furans from the bio341 oil aqueous phase. Levoglucosan and organic acids such as acetic acid can form hydrogen342 bonding with water in the bio-oil aqueous phase [6, 43]. Although chloroform has a high polarity, 343 it barely breaks the hydrogen bond in extraction. However, in the case of ethyl acetate with a 344 slightly higher polarity, when the S/F ratio was increased from 0.5 to 2 , the hydrogen bond 345 between acids and water could be broken, thereby increased the distribution coefficient of acids 346 in ethyl acetate from 0.01 to 0.67 (Fig. 7). Therefore, ethyl acetate at an S/F ratio of 2 would be 347 suitable for extracting acetic acid from BOAP I. The distribution coefficients of phenolics in 348 chloroform were greater than 1.5 at the $\mathrm{S} / \mathrm{F}$ ratios of 0.5 and 1 , and they were greater than 10 at 349 all the investigated S/F ratios in ethyl acetate (Fig. 7), much higher than those in hexane and 
350 petroleum ether, indicating that both chloroform and ethyl acetate are suitable for extracting

351 phenolics from the bio-oil aqueous phase.

352 Based on the above analysis, we further developed a sequential extraction method to

353 separate chemical groups (Fig. 1). First by using chloroform, we can separate furans, alcohols,

354 ketones, and phenolics together (Group 1). Then by using ethyl acetate, we can separate organic

355 acids (Groups 2). Finally, we can recover anhydrosugars (Group 3) from the final aqueous phase

356 of BOAP III. This sequential extraction was investigated and the results are reported in the

357 following section.

358

\subsection{Sequential extraction by chloroform and ethyl acetate}

After chloroform extraction, the number of chromatography peaks of BOAP II was reduced and major peaks observed were levoglucosan, acetic acid, propionic acid, and 1,2-benzenediol.

362 After ethyl acetate extraction of BOAP II, the major peak in BOAP III was only levoglucosan.

363 The chemical compositions of aqueous phase before and after extraction, and the extracted

364 organics are presented in Table 2 and Fig. 8. In this study, about 53.9 wt.\% of total chemicals in

365 BOAP I was quantified. A number of chemicals (46.1 wt.\% of total chemicals) with very low

366 concentration listed in alcohol, ketones, aldehydes, etc., in BOAP I were not quantified. About

36762.2 wt.\% of the total of furans, ketones, alcohols, and phenolics and 85 wt.\% unquantified

368 chemicals in BOAP I were extracted to chloroform. After chloroform extraction, BOAP II was

369 mainly composed of organic acids and levoglucosan, which accounted for about 43.4 wt.\% and

37036.1 wt. $\%$, respectively (Fig. 8). Other components were about 2.0 wt.\% furans, 3.0 wt.\%

371 alcohols, $1.1 \mathrm{wt} \% \%$ phenolics, $0.56 \mathrm{wt} . \%$ ketones, and $13.8 \mathrm{wt} . \%$ unquantified chemicals. The

372 sequential extraction by chloroform followed by ethyl acetate well recovered furans, ketones, 
373 and phenolics from aqueous phase, leaving behind no ketones and only about 0.7 wt.\% furans,

374 and 0.04 wt.\% phenolics in BOAP III after extraction (Fig. 8). The sequential extraction also

375 concentrated levoglucosan resulting in about 53 wt.\% levoglucosan in BOAP III. However, we

376 also observed that BOAP III contained about 32.5 wt.\% organic acids. In this study, BOAP II

377 was extracted only once by ethyl acetate. Multiple extractions using ethyl acetate may be

378 implemented to extract larger fraction of acids from BOAP II. The organics extracted by

379 chloroform were mainly furans, ketones, alcohols, phenolics. Due to the very low concentration

380 of these compounds, it will be difficult to further purify them individually. The preferred

381 application of these compounds could be as a feedstock for the biorefinery process to generate

382 hydrocarbons fuels. The organics extracted by ethyl acetate contains over $57.6 \mathrm{wt} \%$ organic

383 acids, in which acetic acid accounts for about $75 \mathrm{wt} \%$. It will be costly to produce glacial acetic

384 acid from this stream. Therefore, these organics could serve as a source for hydrogen production 385 using microbial electrolysis [16].

386

\section{Conclusions}

Four organic solvents were evaluated for chemical extraction from bio-oil aqueous phase.

389 The amount of chemicals extracted by these four solvents from bio-oil aqueous phase was in the 390 order of hexane $<$ petroleum $<$ chloroform $<$ ether ethyl acetate at the same S/F ratio. Further, 391 chloroform had similar extraction efficiency with ethyl acetate for furans, alcohols, ketones and 392 phenolics. Ethyl acetate also had high extraction efficiency for acetic acid when the S/F ratio was 393 at 2. According to the distribution coefficients and extraction efficiencies obtained for the 394 different chemical groups, a sequential extraction using chloroform followed by ethyl acetate is 395 recommended. The first step of extraction using chloroform separated most of the furans, 396 ketones, alcohols, and phenolics from bio-oil aqueous phase. The second step of extraction 
employing ethyl acetate concentrated organic acids (over $62 \mathrm{wt} \%$ acetic acid in BOAP I). In the

398 final aqueous phase, levoglucosan was concentrated at $53 \mathrm{wt} . \%$. These results suggest that

399 sequential extraction with different solvents can be used to separate chemical groups in bio-oil

400 aqueous phase and these extracted chemical groups could serve as feedstocks for the specific

401 production of chemicals, hydrogen, or hydrocarbons.

\section{Acknowledgements}

403 We acknowledge funding for this work from the U.S. Department of Energy, BioEnergy

404 Technologies Office under the Carbon, Hydrogen and Separations Efficiency (CHASE) in Bio-

405 Oil Conversion Pathways program, DE-FOA-0000812. The manuscript is coauthored by UT-

406 Battelle, LLC, under Contract DEAC05-00OR22725 with the U.S. Department of Energy. The

407 authors also thank Drs. Pyoungchung Kim and Nicole Labbe at the University of Tennessee

408 Center of Renewable Carbon for help in the production of bio-oil.

\section{References}

410 [1] E.d. Jong, A. Higson, P. Walsh, M. Wellisch, Bio-based chemicals: value added products

411 from biorefineries, in: IEA Bioenergy/Task 42 Biorefinery, 2012,

412 http://www.ieabioenergy.com/publications/bio-based-chemicals-value-added-products-from-

413 biorefineries/.

414 [2] C.B. Rasrendra, B. Girisuta, H.H. van de Bovenkamp, J.G.M. Winkelman, E.J. Leijenhorst,

415 R.H. Venderbosch, M. Windt, D. Meier, H.J. Heeres, Recovery of acetic acid from an aqueous

416 pyrolysis oil phase by reactive extraction using tri- $n$-octylamine, Chem Eng J, 176-177 (2011)

$417 \quad 244-252$.

418 [3] Q. Zhang, J. Chang, T.J. Wang, Y. Xu, Review of biomass pyrolysis oil properties and 419 upgrading research, Energ Convers Manage, 48 (2007) 87-92. 
420 [4] C.A. Mullen, G.D. Strahan, A.A. Boateng, Characterization of various fast-pyrolysis bio-oils 421 by NMR spectroscopy, Energ Fuel, 23 (2009) 2707-2718.

422 [5] D. Mohan, C.U. Pittman, P.H. Steele, Pyrolysis of wood/biomass for bio-oil: A critical 423 review, Energ Fuel, 20 (2006) 848-889.

424 [6] C.R. Vitasari, G.W. Meindersma, A.B. de Haan, Water extraction of pyrolysis oil: The first 425 step for the recovery of renewable chemicals, Bioresource Technol, 102 (2011) 7204-7210. 426 [7] Y. Wei, H.W. Lei, L. Wang, L. Zhu, X.S. Zhang, Y.P. Liu, S.L. Chen, B. Ahring, Liquid427 liquid extraction of biomass pyrolysis bio-oil, Energ Fuel, 28 (2014) 1207-1212.

428 [8] R. Xu, L. Ferrante, C. Briens, F. Berruti, Bio-oil production by flash pyrolysis of sugarcane 429 residues and post treatments of the aqueous phase, J Anal Appl Pyrol, 91 (2011) 263-272.

430 [9] L.K.E. Park, S.J. Ren, S. Yiacoumi, X.P. Ye, A.P. Borole, C. Tsouris, Separation of 431 Switchgrass Bio-Oil by Water/Organic Solvent Addition and pH Adjustment, Energ Fuel, 30 432 (2016) 2164-2173.

433 [10] H.Y. Li, Q.L. Xu, H.S. Xue, Y.J. Yan, Catalytic reforming of the aqueous phase derived 434 from fast-pyrolysis of biomass, Renew Energ, 34 (2009) 2872-2877.

435 [11] P.N. Kechagiopoulos, S.S. Voutetakis, A.A. Lemonidou, I.A. Vasalos, Hydrogen production 436 via reforming of the aqueous phase of bio-oil over Ni/olivine catalysts in a spouted bed reactor, 437 Ind Eng Chem Res, 48 (2009) 1400-1408.

438 [12] P.N. Kechagiopoulos, S.S. Voutetakis, A.A. Lemonidou, I.A. Vasalos, Hydrogen production 439 via steam reforming of the aqueous phase of bio-oil in a fixed bed reactor, Energ Fuel, 20 (2006) $440 \quad 2155-2163$. 
441 [13] F.H. Mahfud, F.P. van Geel, R.H. Venderbosch, H.J. Heeres, Acetic acid recovery from fast 442 pyrolysis oil. An exploratory study on liquid-liquid reactive extraction using aliphatic tertiary 443 amines, Sep Sci Technol, 43 (2008) 3056-3074.

444 [14] Y. Feng, D. Meier, Extraction of value-added chemicals from pyrolysis liquids with 445 supercritical carbon dioxide, J Anal Appl Pyrol, 113 (2015) 174-185.

446 [15] J.N. Lian, M. Garcia-Perez, S.L. Chen, Fermentation of levoglucosan with oleaginous yeasts 447 for lipid production, Bioresource Technol, 133 (2013) 183-189.

448 [16] A.J. Lewis, S. Ren, X. Ye, P. Kim, N. Labbe, A.P. Borole, Hydrogen production from 449 switchgrass via a hybrid pyrolysis-microbial electrolysis process, Bioresource Technol, 195 $450 \quad$ (2015) 231-241.

451 [17] A. Thygesen, F.W. Poulsen, I. Angelidaki, B. Min, A.B. Bjerre, Electricity generation by 452 microbial fuel cells fuelled with wheat straw hydrolysate, Biomass Bioenerg, 35 (2011) 4732 4534739.

454 [18] Z.Y. Chi, M. Rover, E. Jun, M. Deaton, P. Johnston, R.C. Brown, Z.Y. Wen, L.R. Jarboe, 455 Overliming detoxification of pyrolytic sugar syrup for direct fermentation of levoglucosan to 456 ethanol, Bioresource Technol, 150 (2013) 220-227.

457 [19] J.A. Capunitan, S.C. Capareda, Characterization and separation of corn stover bio-oil by 458 fractional distillation, Fuel, 112 (2013) 60-73.

459 [20] Y. Elkasabi, C.A. Mullen, A.A. Boateng, Distillation and isolation of commodity chemicals 460 from bio-oil made by tail-gas reactive pyrolysis, Acs Sustain Chem Eng, 2 (2014) 2042-2052.

461 [21] F.X. Zeng, W.J. Liu, H. Jiang, H.Q. Yu, R.J. Zeng, Q.X. Guo, Separation of phthalate esters 462 from bio-oil derived from rice husk by a basification-acidification process and column 463 chromatography, Bioresource Technol, 102 (2011) 1982-1987. 
464 [22] J.S. Kim, Production, separation and applications of phenolic-rich bio-oil - A review,

465 Bioresource Technol, 178 (2015) 90-98.

466 [23] L.F. Zilnik, A. Jazbinsek, Recovery of renewable phenolic fraction from pyrolysis oil, Sep

467 Purif Technol, 86 (2012) 157-170.

468 [24] M. Garcia-Perez, A. Chaala, H. Pakdel, D. Kretschmer, C. Roy, Characterization of bio-oils

469 in chemical families, Biomass Bioenerg, 31 (2007) 222-242.

470 [25] P. Kim, A. Johnson, C.W. Edmunds, M. Radosevich, F. Vogt, T.G. Rials, N. Labbe, Surface

471 functionality and carbon structures in lignocellulosic-derived biochars produced by fast pyrolysis,

472 Energ Fuel, 25 (2011) 4693-4703.

473 [26] S.J. Ren, X.P. Ye, A.P. Borole, P. Kim, N. Labbe, Analysis of switchgrass-derived bio-oil

474 and associated aqueous phase generated in a semi-pilot scale auger pyrolyzer, J Anal Appl Pyrol, 475119 (2016) 97-103.

476 [27] ASTM D1217-12, Standard test method for density and relative density (specific gravity) of

477 liquids by bingham pycnometer, ASTM International, West Conshohocken, PA, 2012,

$478 \quad$ www.astm.org.

479 [28] ASTM D4377-00(2011), Standard test method for water in crude oils by potentiometric

480 Karl Fischer titration, ASTM International, West Conshohocken, PA, 2011, www.astm.org.

481 [29] ASTM D445-12, Standard test method for kinematic viscosity of transparent and opaque

482 liquids (and calculation of dynamic viscosity), ASTM International, West Conshohocken, PA,

483 2012, www.astm.org.

484 [30] ASTM D482-13, Standard test method for ash from petroleum products, ASTM

485 International, West Conshohocken, PA, 2013, www.astm.org. 
[31] M.E. Boucher, A. Chaala, C. Roy, Bio-oils obtained by vacuum pyrolysis of softwood bark as a liquid fuel for gas turbines. Part I: Properties of bio-oil and its blends with methanol and a pyrolytic aqueous phase, Biomass Bioenerg, 19 (2000) 337-350.

[32] ASTM D664-11a, Standard test method for acid number of petroleum products by potentiometric titration, ASTM International, West Conshohocken, PA, 2011, www.astm.org. [33] S.H. Ha, N.L. Mai, Y.M. Koo, Butanol recovery from aqueous solution into ionic liquids by liquid-liquid extraction, Process Biochem, 45 (2010) 1899-1903.

[34] R.H. He, P. Ye, B.C. English, J.A. Satrio, Influence of pyrolysis condition on switchgrass bio-oil yield and physicochemical properties, Bioresource Technol, 100 (2009) 5305-5311. [35] T. Imam, S. Capareda, Characterization of bio-oil, syn-gas and bio-char from switchgrass pyrolysis at various temperatures, J Anal Appl Pyrol, 93 (2012) 170-177.

[36] C.A. Mullen, A.A. Boateng, Chemical composition of bio-oils produced by fast pyrolysis of two energy crops, Energ Fuel, 22 (2008) 2104-2109.

[37] S. Thangalazhy-Gopakumar, S. Adhikari, R.B. Gupta, S.D. Fernando, Influence of Pyrolysis Operating Conditions on Bio-Oil Components: A Microscale Study in a Pyroprobe, Energ Fuel, 25 (2011) 1191-1199.

[38] V.L. Budarin, J.H. Clark, B.A. Lanigan, P. Shuttleworth, S.W. Breeden, A.J. Wilson, D.J. Macquarrie, K. Milkowski, J. Jones, T. Bridgeman, A. Ross, The preparation of high-grade biooils through the controlled, low temperature microwave activation of wheat straw, Bioresource Technol, 100 (2009) 6064-6068.

[39] F. Ates, M.A. Isikdag, Evaluation of the role of the pyrolysis temperature in straw biomass samples and characterization of the oils by GUMS, Energ Fuel, 22 (2008) 1936-1943. 
508 [40] P.G. Duan, P.E. Savage, Catalytic treatment of crude algal bio-oil in supercritical water:

509 optimization studies, Energ Environ Sci, 4 (2011) 1447-1456.

510 [41] M.C. Samolada, A. Papafotica, I.A. Vasalos, Catalyst evaluation for catalytic biomass

511 pyrolysis, Energ Fuel, 14 (2000) 1161-1167.

512 [42] Mortimer J. Kamlet, R.W. Taft, The solvatochromic comparison method. I. The $\beta$-scale of

513 solvent hydrogen-bond acceptor (HBA) basicities, Journal of the American chemical Society, 98, $514 \quad$ (1976) 377-383.

515 [43] L. Pu, Y.M. Sun, Z.B. Zhang, Hydrogen bonding of single acetic acid with water molecules 516 in dilute aqueous solutions, Sci China Ser B, 52 (2009) 2219-2225. 
529 Figure 1. (A) Experimental procedures for the production of bio-oil and sequential extraction of 530 chemical groups from the aqueous phase (BOAP I-III), and (B) their envisaged applications for 531 the production of fuels and chemicals.

532 Figure 2. Chemical distribution (relative peak area percentage analyzed by GC/MS) in BOAP I.

533 Figure 3. The mass percentage of chemicals extracted by different organic solvents and S/F 534 ratios.

535 Figure 4. Extraction efficiencies for levoglucosan, acetic acid, and propionic acid in BOAP I by 536 different solvents and $\mathrm{S} / \mathrm{F}$ ratios.

537 Figure 5. Extraction efficiencies for alcohols, ketones, and furans in BOAP I by different 538 solvents and $\mathrm{S} / \mathrm{F}$ ratios.

539 Figure 6. Extraction efficiencies for phenolics in BOAP I by different solvents and S/F ratios.

540 Figure 7. Distribution coefficients for chemical groups from BOAP I in different solvents.

541 Distribution coefficients reported are average numbers based on three replicates.

542 Figure 8. Chemical compositions of aqueous phase before and after sequential extraction and the 543 extracted organics in solvents.

544

545

546

547

548

549

550

551

552 


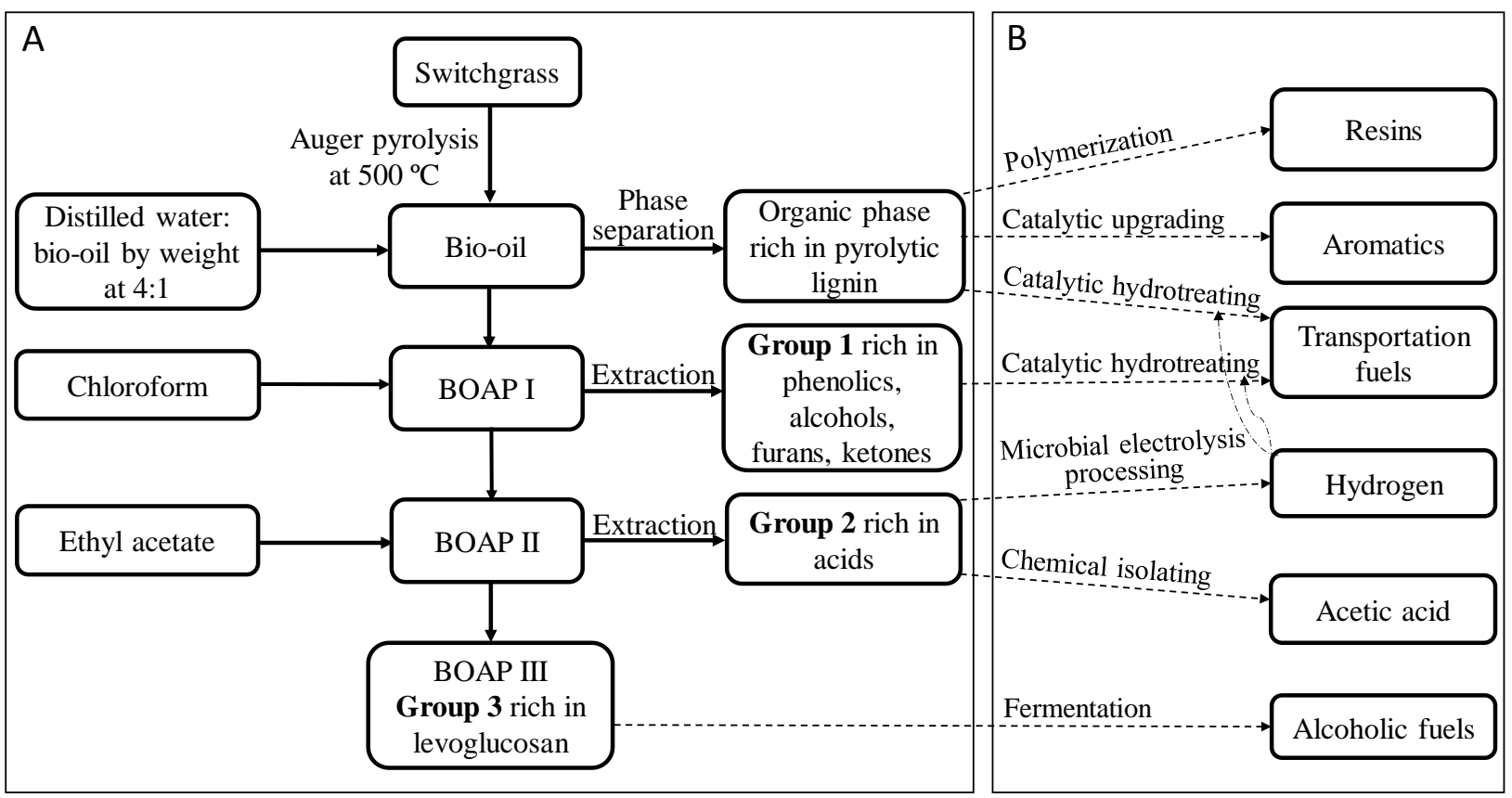
the production of fuels and chemicals. 


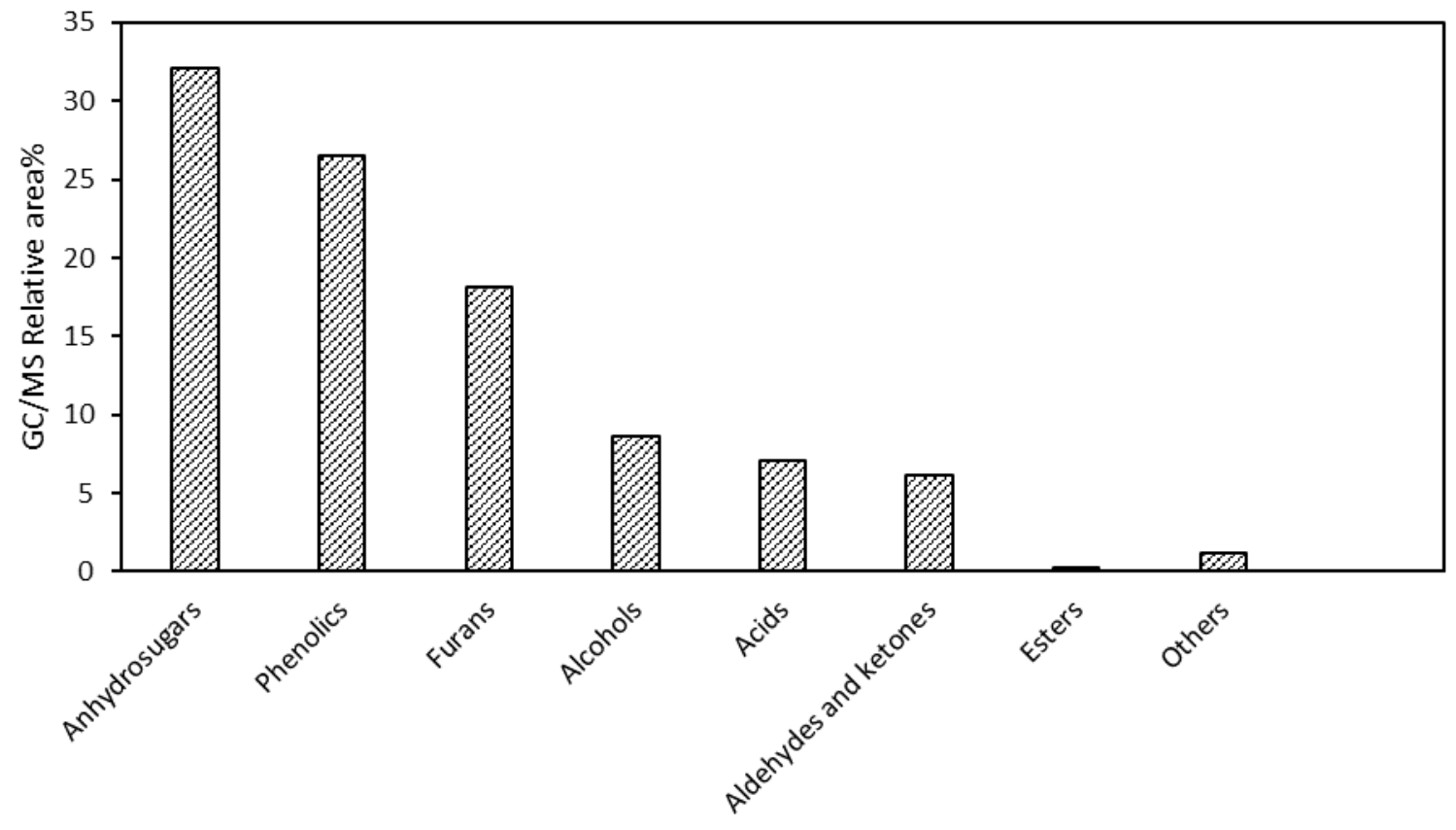

569

570 Figure 2. Chemical distribution (relative peak area percentage analyzed by GC/MS) in BOAP I

571

572

573

574

575

576

577

578

579

580

581 


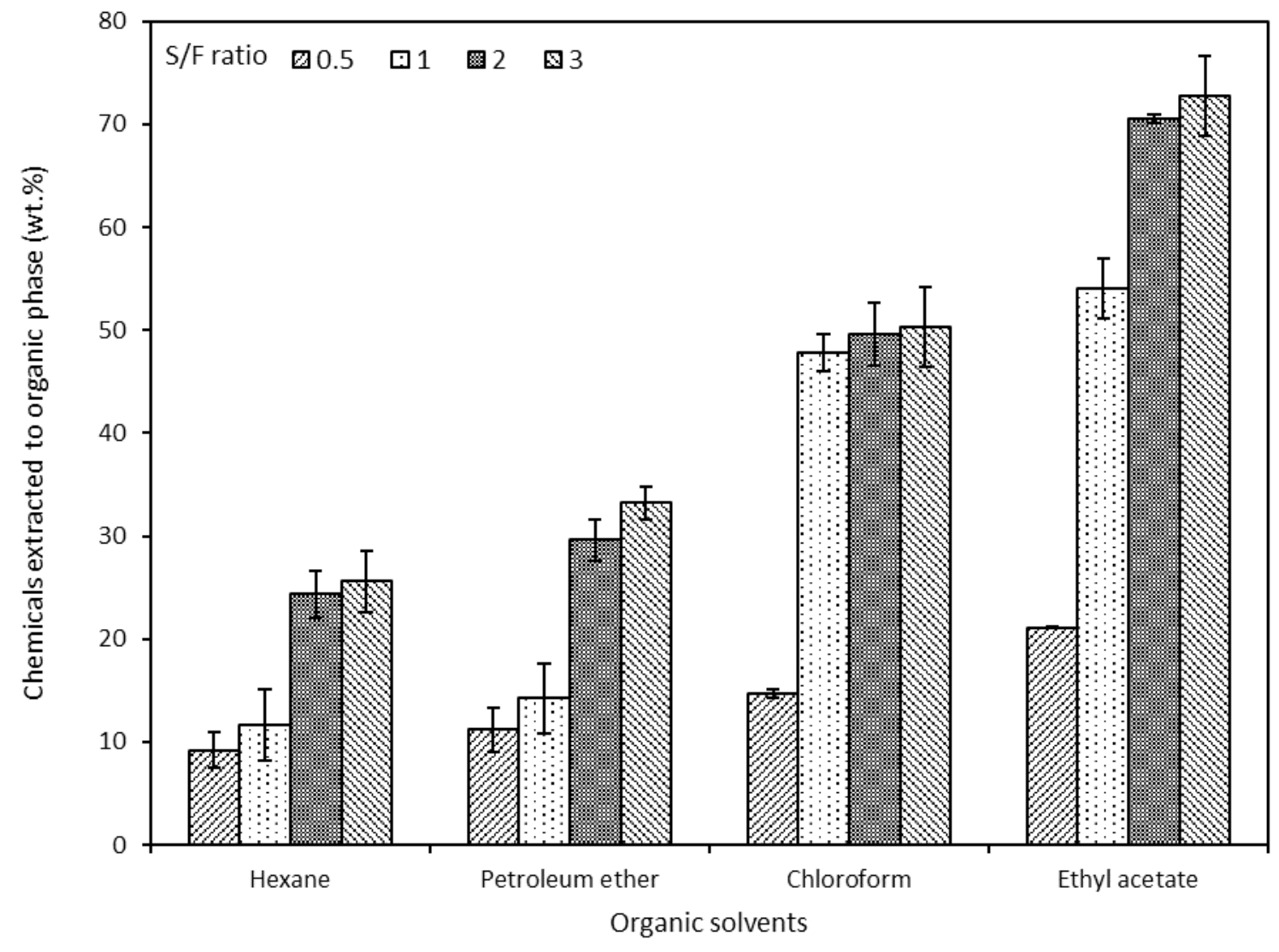

583 Figure 3. The mass percentage of total chemicals extracted by different organic solvents and S/F 584 ratios

585

586

587

588

589

590

591

592

593 

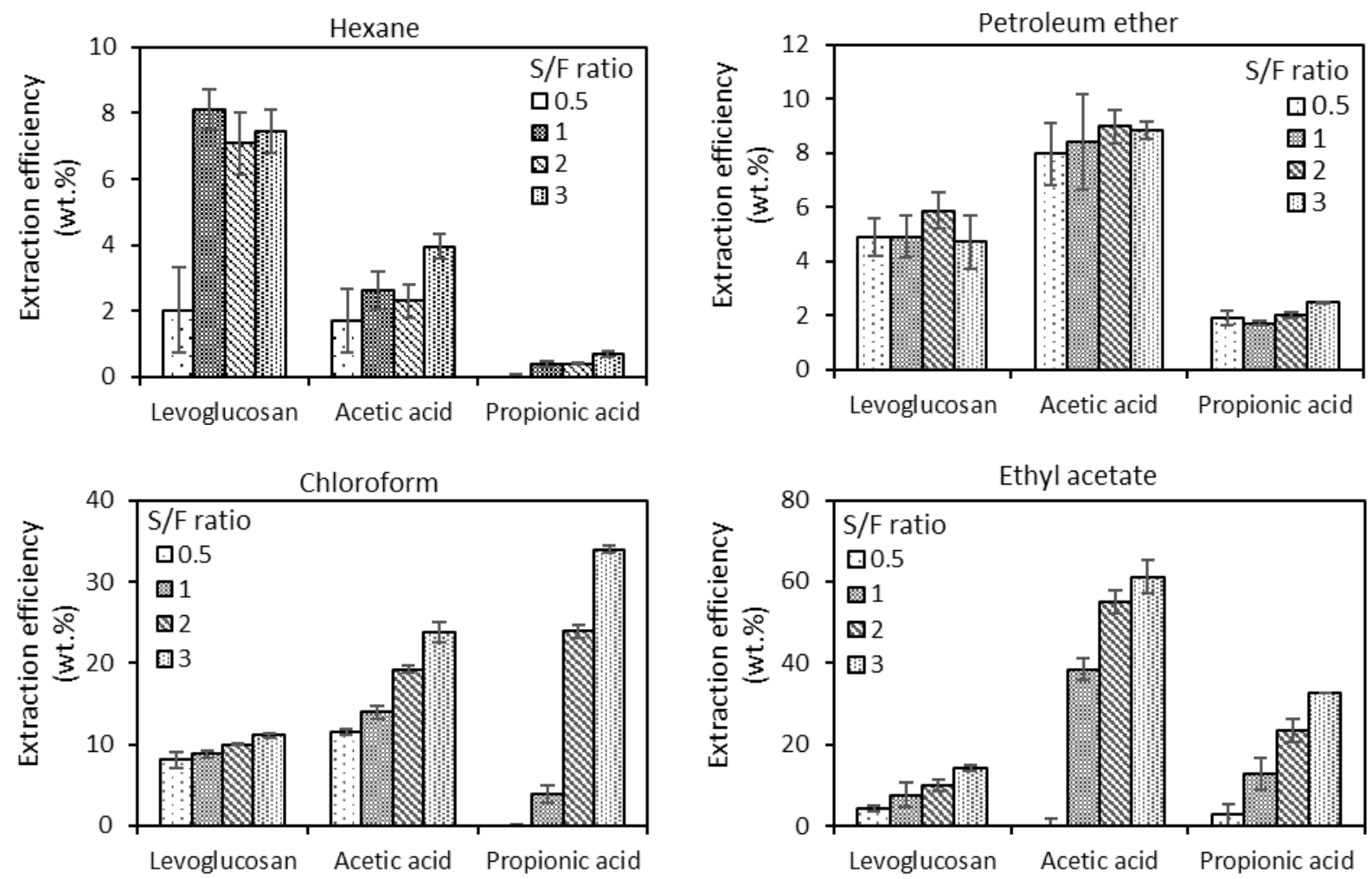

Figure 4. Extraction efficiencies for levoglucosan, acetic acid, and propionic acid in BOAP I by different solvents and $\mathrm{S} / \mathrm{F}$ ratios

598

599

600

601

602

603

604 

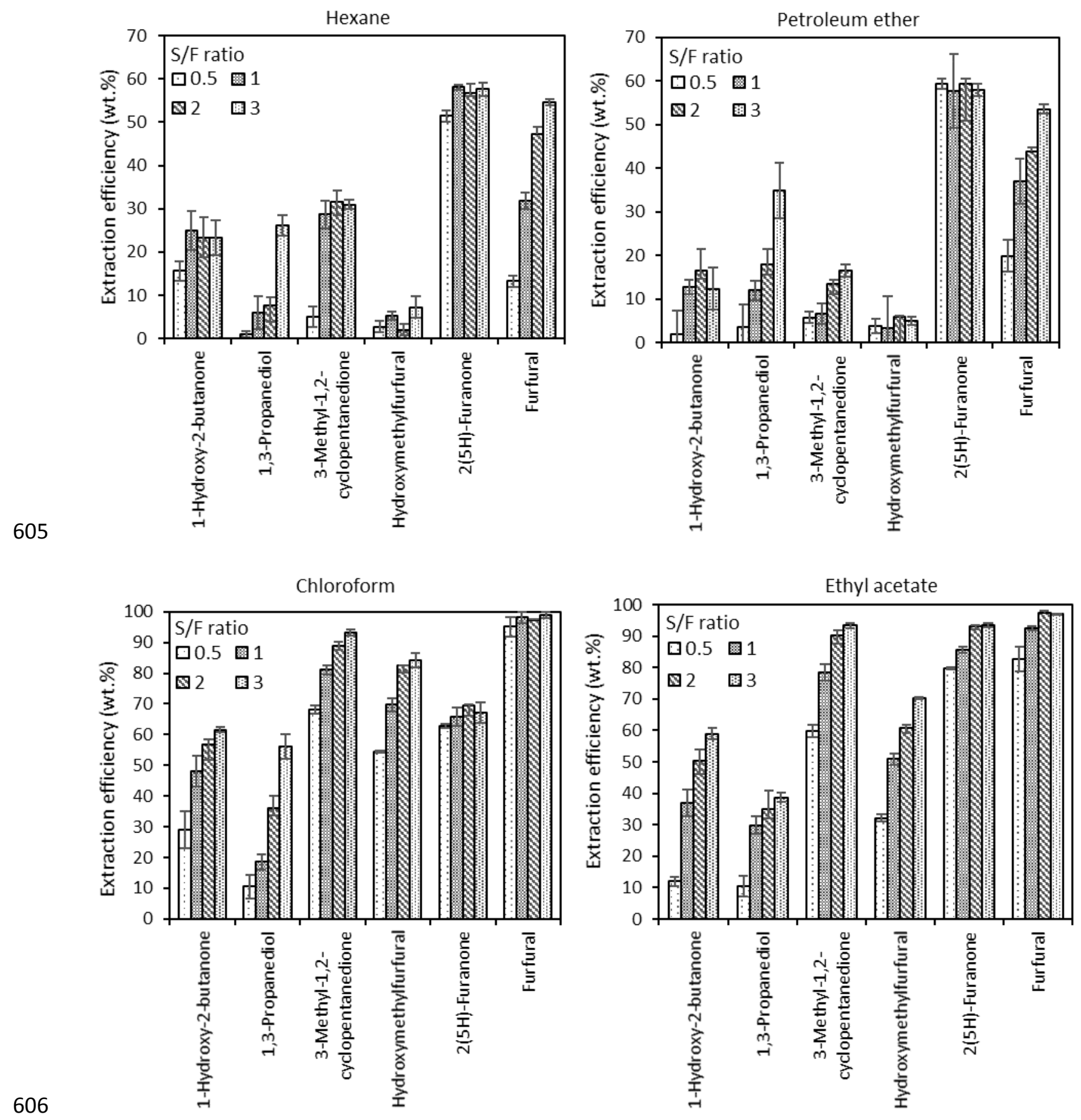

607

608 Figure 5. Extraction efficiencies for alcohols, ketones, and furans in BOAP I by different 609 solvents and $\mathrm{S} / \mathrm{F}$ ratios 

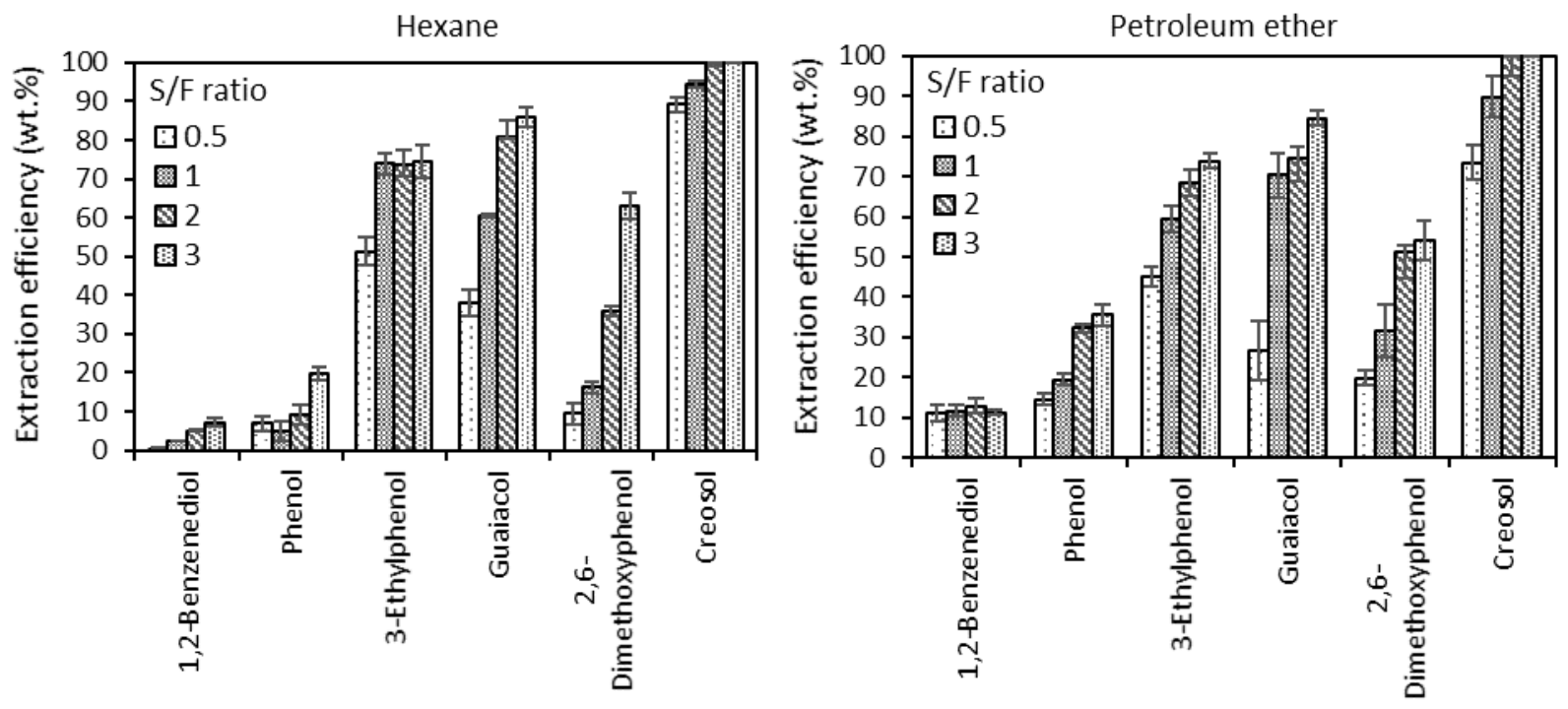

612
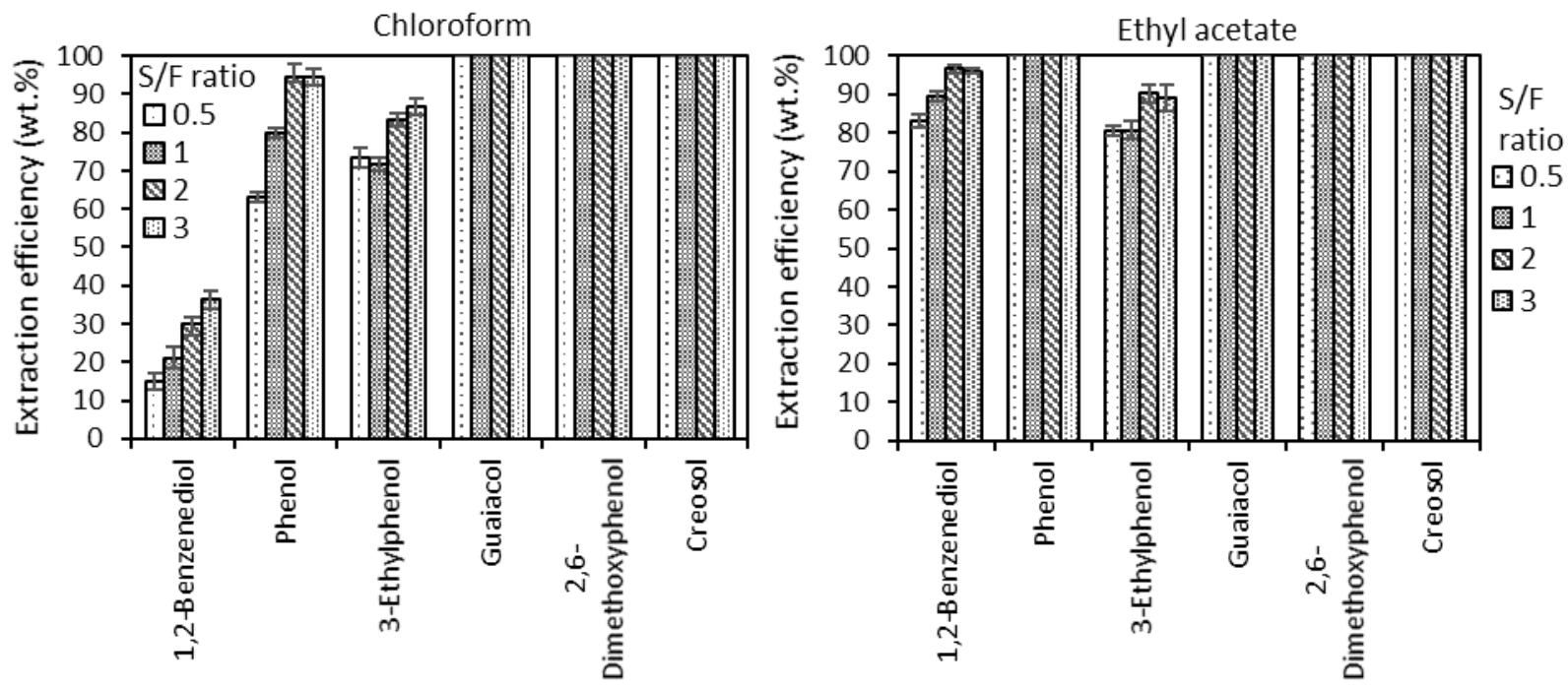

613

Figure 6. Extraction efficiencies for phenolics in BOAP I by different solvents and S/F ratios

615

616

617

618

619

620

621 

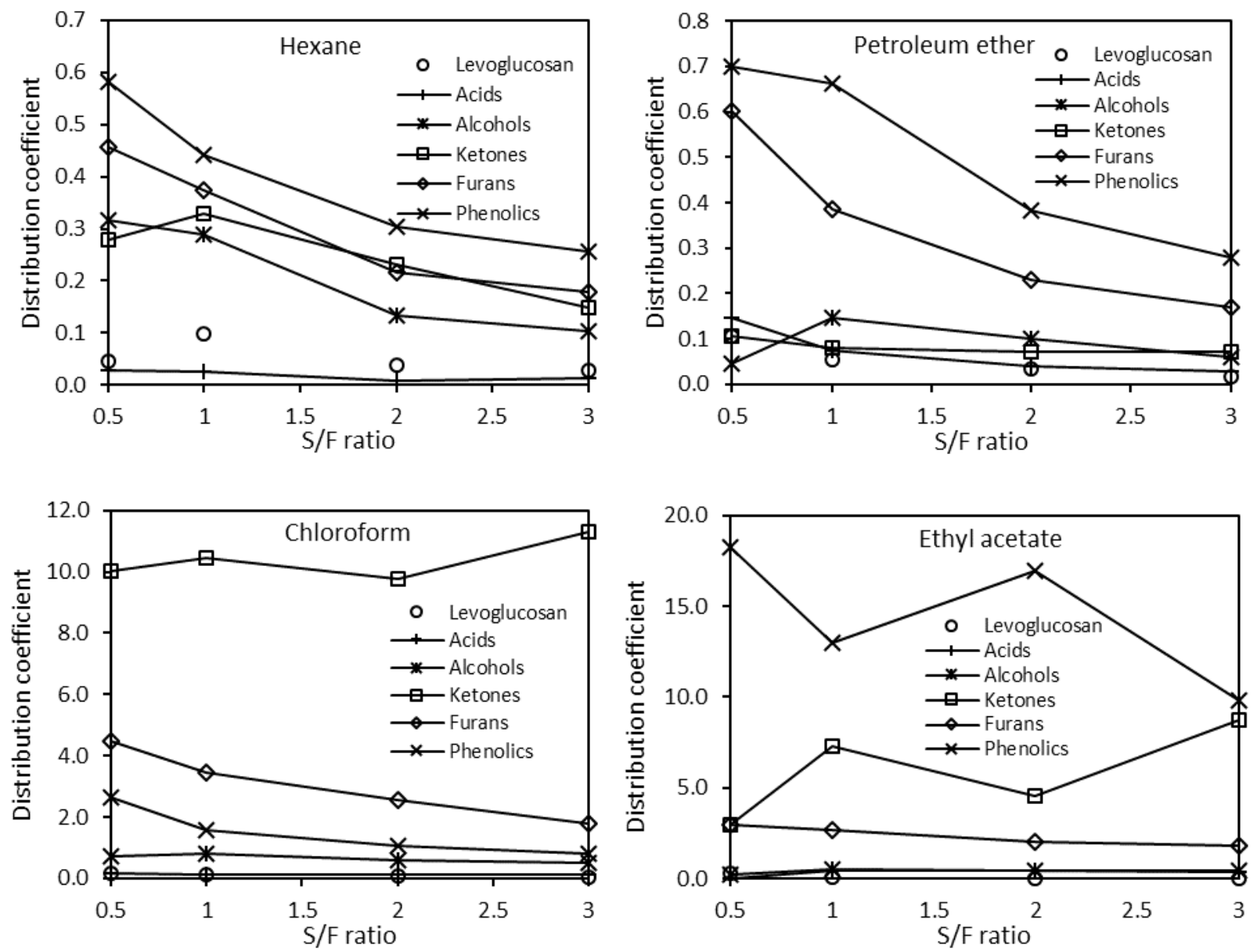

624 Figure 7. Distribution coefficients for chemical groups from BOAP I in different solvents. Distribution coefficients reported are average numbers based on three replicates.

626

627

628

629

630

631

632 


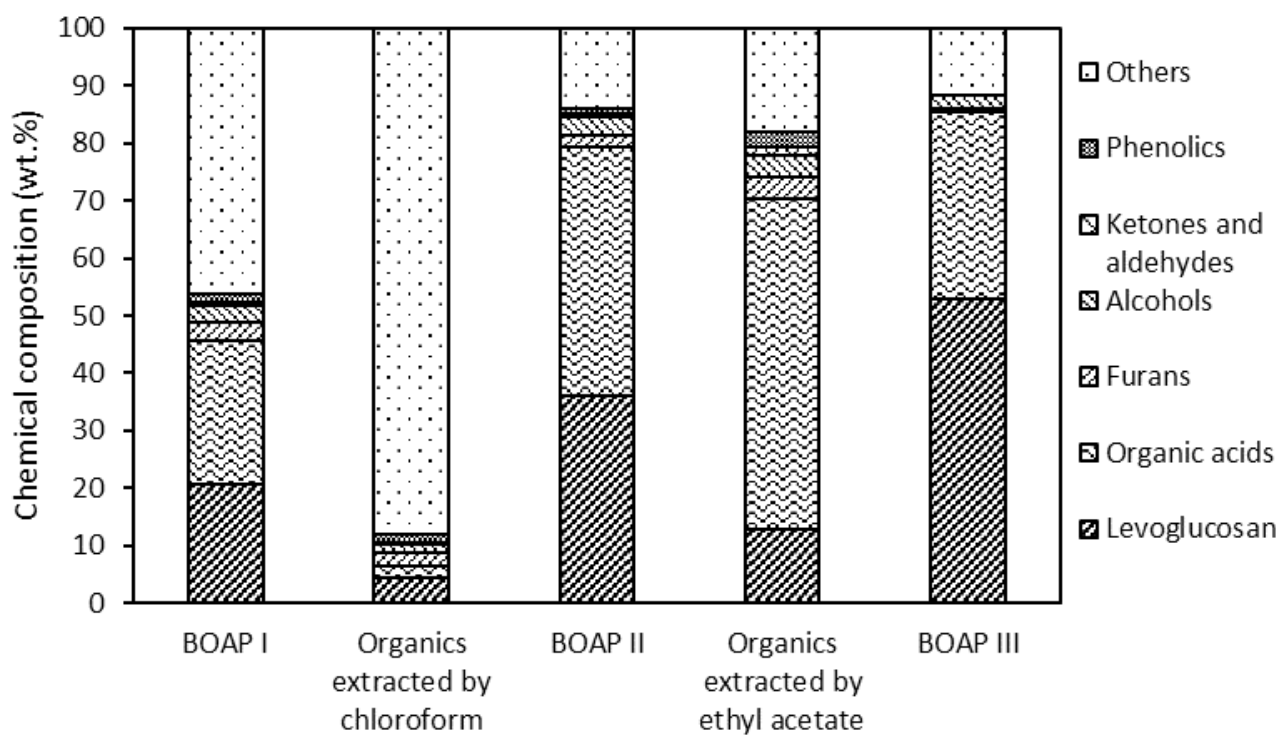

635 Figure 8. Chemical compositions of aqueous phase before and after sequential extraction and the

636 extracted organics in solvents

637

638

639

640

641

642

643

644

645

646

647

648

649 
Table 1. Properties of crude bio-oil and BOAP I (Deionized water added at 4:1 by weight for 652 BOAP I separation)

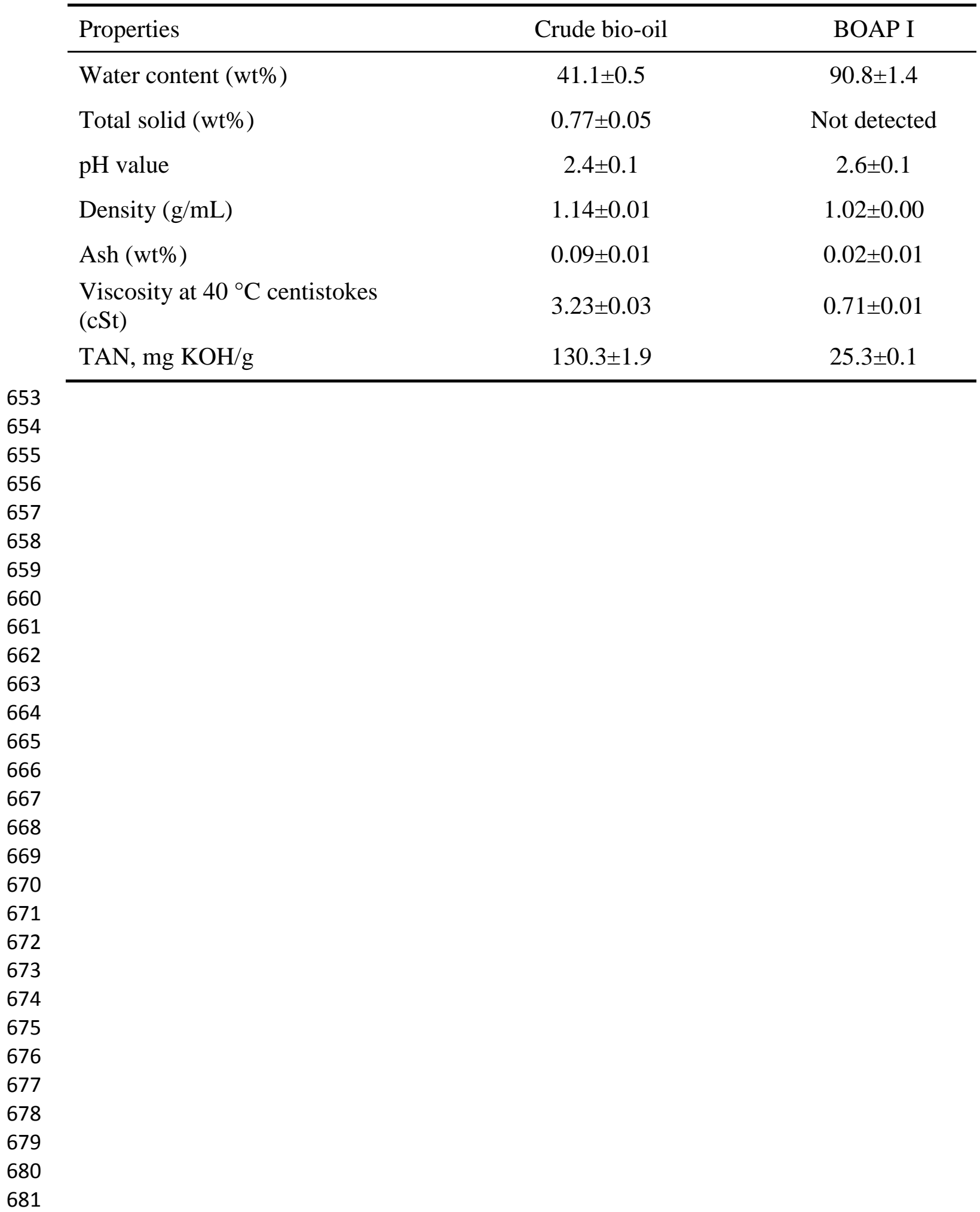


683 Table 2. Concentrations of 15 compounds quantified in BOAP I, BOAP II (aqueous fraction 684 produced post chloroform extraction), and BOAP III (aqueous fraction remaining after ethyl 685 acetate extraction). Data reported are average numbers based on three replicates.

\begin{tabular}{|c|c|c|c|c|}
\hline Classifications & Major compounds & $\begin{array}{c}\text { Concentration in } \\
\text { BOAP I } \\
(\mathrm{g} / \mathrm{L})\end{array}$ & $\begin{array}{c}\text { Concentration } \\
\text { in BOAP II } \\
(\mathrm{g} / \mathrm{L})\end{array}$ & $\begin{array}{c}\text { Concentration } \\
\text { in BOAP III } \\
(\mathrm{g} / \mathrm{L})\end{array}$ \\
\hline \multirow[t]{2}{*}{ Acids } & Acetic acid & 16.54 & 14.64 & 6.26 \\
\hline & Propionic acid & 6.37 & 6.35 & 3.93 \\
\hline Anhydrosugars & Levoglucosan & 18.99 & 17.46 & 16.62 \\
\hline \multirow[t]{3}{*}{ Furans } & Furfural & 0.98 & 0.05 & BDL \\
\hline & 2(5H)-Furanone & 0.82 & 0.31 & 0.04 \\
\hline & Hydroxymethylfurfural & 1.37 & 0.62 & 0.17 \\
\hline Alcohols & 1-Hydroxy-2-butanone & 2.25 & 1.17 & 0.51 \\
\hline Ketones & $\begin{array}{l}\text { 1,3-Propanediol } \\
\text { 3-Methyl-1,2- } \\
\text { cyclopentanedione }\end{array}$ & $\begin{array}{l}0.35 \\
0.40\end{array}$ & $\begin{array}{l}0.29 \\
0.27\end{array}$ & $\begin{array}{c}0.18 \\
\text { BDL }\end{array}$ \\
\hline \multirow[t]{6}{*}{ Phenolics } & 1,2-Benzenediol & 0.63 & 0.54 & 0.01 \\
\hline & Phenol & 0.15 & BDL & BDL \\
\hline & Guaiacol & 0.20 & $\mathrm{BDL}$ & BDL \\
\hline & Creosol & 0.15 & BDL & $\mathrm{BDL}$ \\
\hline & 2,6-Dimethoxyphenol & 0.17 & BDL & BDL \\
\hline & 3-Ethylphenol & 0.20 & $\mathrm{BDL}$ & $\mathrm{BDL}$ \\
\hline
\end{tabular}

BDL: The concentrations are below the detection limit.

687

688

689

690

691

692

693

694

695

696

697

698

699

700 
702 Table 3. Extraction efficiency of different solvents for 15 quantified chemicals at the optimum 703 conditions. Data reported are average numbers based on three replicates.

\begin{tabular}{|c|c|c|c|c|c|c|}
\hline & & \multirow[b]{2}{*}{ Major compounds } & \multicolumn{4}{|c|}{ Extraction efficiency (wt.\%) } \\
\hline & & & $\begin{array}{c}\text { Hexane } \\
(2: 1)^{\mathrm{a}}\end{array}$ & $\begin{array}{l}\text { Petroleum } \\
\text { ether }(2: 1)\end{array}$ & $\begin{array}{l}\text { Chloroform } \\
(1: 1)\end{array}$ & $\begin{array}{c}\text { Ethyl } \\
\text { acetate } \\
(2: 1)\end{array}$ \\
\hline \multirow[t]{12}{*}{ Group 1} & \multirow[t]{3}{*}{ Furans } & Furfural & 56.8 & 43.9 & 98.1 & 97.3 \\
\hline & & 2(5H)-Furanone & 47.3 & 59.4 & 65.8 & 93.1 \\
\hline & & Hydroxymethylfurfural & 1.8 & 5.9 & 69.6 & 60.8 \\
\hline & \multirow[t]{2}{*}{ Alcohols } & 1-Hydroxy-2-butanone & 23.3 & 16.5 & 48.1 & 50.4 \\
\hline & & 1,3-Propanediol & 7.7 & 17.9 & 18.6 & 35.0 \\
\hline & Ketones & $\begin{array}{l}\text { 3-Methyl-1,2- } \\
\text { cyclopentanedione }\end{array}$ & 31.7 & 13.5 & 81.0 & 90.1 \\
\hline & \multirow[t]{6}{*}{ Phenolics } & 1,2-Benzenediol & 5.1 & 12.6 & 21.1 & 96.7 \\
\hline & & Phenol & 9.1 & 32.6 & 79.8 & 100.0 \\
\hline & & 3-Ethylphenol & 73.5 & 68.5 & 71.8 & 90.3 \\
\hline & & Guaiacol & 80.7 & 74.4 & 100.0 & 100.0 \\
\hline & & 2,6-Dimethoxyphenol & 36.1 & 51.2 & 100.0 & 100.0 \\
\hline & & Creosol & 100.0 & 100.0 & 100.0 & 100.0 \\
\hline \multirow[t]{2}{*}{ Group 2} & \multirow[t]{2}{*}{ Acids } & Acetic acid & 1.3 & 9.0 & 14.0 & 55.0 \\
\hline & & Propionic acid & 0.4 & 1.2 & 3.9 & 23.3 \\
\hline Group 3 & $\begin{array}{l}\text { Anhydro- } \\
\text { sugars }\end{array}$ & Levoglucosan & 7.1 & 5.9 & 8.8 & 7.6 \\
\hline
\end{tabular}




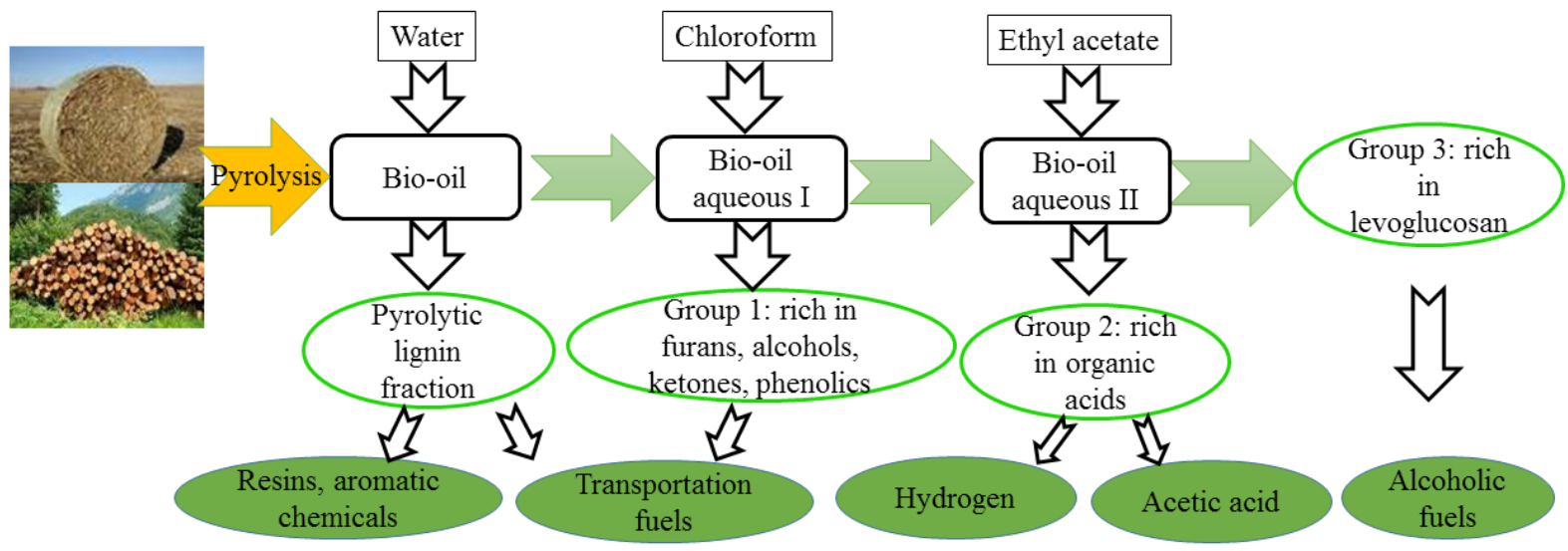

